\title{
An Insight on Salting-out Assisted Liquid-Liquid Extraction for Phytoanalysis
}

\author{
Inês M. Valente \\ Manuela M. Moreira \\ Pâmela Neves \\ Thiago da Fé \\ Luís M. Gonçalves \\ Paulo J. Almeida \\ José A. Rodrigues
}

\section{Abstract}

Introduction

Salting-out assisted liquid-liquid extraction (SALLE) is a technique that, although simple and not requiring any complex equipment, is very powerful and versatile. It has obtained growing interest in bioanalysis particularly when combined with chromatographic techniques.

Objectives

Herein, fennel seeds (Foeniculum vulgare Mill.) were used as a case-study to show the application of SALLE in phytochemical analysis.

Material and Methods

SALLE combined with HPLC-UV-MS/MS and GC-MS.

Results

By HPLC-UV-MS/MS analysis of the organic extract it was possible to identify various phenolic compounds, including quercetin derivatives, caffeic acid, p-coumaric acid and chlorogenic acid. The main compounds identified by GC-MS were estragole, fenchone, anisaldehyde, anethole, benzaldehyde, camphor and apiole.

Conclusion

HPLC and GC analysis of the extracts showed that it is possible to isolate, in only one step, a wide range of compounds with distinct properties, allowing a detailed phytochemical analysis.

\section{Keywords}

chromatography; Foeniculum vulgare; phytochemical characterisation; polyphenols; sample preparation 


\section{Introduction}

The extraction and characterisation of active compounds from plants have resulted in the discovery of several compounds with therapeutic value or even new sources for already known compounds (Huie, 2002). For the identification of new compounds, sample preparation is a crucial first step (Huie, 2002). Therefore, considering the economic importance of plants and the increasing relevance of medicinal plants, it is not surprising that a lot of research in this field has employed techniques like solid-phase micro-extraction, supercritical-fluid extraction, pressurised-liquid extraction, microwaveassisted extraction, solid-phase extraction, and surfactant-mediated extraction (Huie, 2002). Another option, somewhat simpler and cheaper yet very powerful, is salting-out assisted liquid-liquid extraction (SALLE) (Valente et al., 2013a). The salting-out effect has an interesting application for the creation of liquid biphasic systems in mixtures composed of water and water-miscible organic solvents. Adding salts, two distinguishable liquid phases are formed in which the upper phase is mainly composed of the organic solvent. Although its initial applications can be traced to the 1970s (Matkovich and Christian 1973), new analytical methodologies using the salting-out effect continue to be developed, as is the case in the field of biotechnology where the precipitation of proteins in biological samples is aimed (Ahmed and Mahmoud, 2015; Yang et al., 2015). Moreover, it is not in any way misplaced to state that the QuEChERS (portmanteau word formed from "Quick, Easy, Cheap, Effective, Ruged and Safe") method embody the SALLE concept (Silva et al., 2012; Valente et al., 2013b). Of course, this type of sample preparation, where analytes are concentrated and incorporated in cleaner matrices that are more column-friendly, is ideal for good chromatographic separations targeted for chemical analysis.

Fennel (Foeniculum vulgare Mill.) is a popular plant in Mediterranean cuisine; it is crunchy with a minor sweet flavour, and owns a pleasant odour (Steuer and Schulz, 2003; Díaz-Maroto et al., 2006; Miguel et al., 2010; Azevedo et al., 2012). Most of the plant (bulb, leaves, seeds and stalk) is edible, with a considerable content of vitamin $\mathrm{C}$ and fibre. Fennel belongs to the Apiaceae family (also known as Umbelliferae), the same that includes plants like parsley, parsnip, cumin, carrot and many other widely known plants, not all of them edible as is clearly the case of hemlock. Many health applications are attributed to fennel, from antispasmodic to diuretic or anti-inflammatory properties (Gori et al., 2012); however most of these claims have not been subject to serious studies. Nevertheless some trials can be found in the literature advocating, for example, minor therapeutic effects for dysmenorrhoea (Jahromi et al., 2003) or hirsutism (Akha et al., 2014).

Herein, SALLE was applied to the phytochemical study of fennel seeds as a proof-of-concept of the capabilities of this technique applied to plants' chemical analysis. Extracts were then subsequently analysed by liquid and gas chromatography (LC and GC), both coupled to mass spectrometry (MS) detection.

\section{Material and methods \\ Chemicals and samples}

High-purity water (resistivity not lower than $18.2 \mathrm{M} \Omega \mathrm{cm}$ ), from a Direct-Q $3 \mathrm{UV}$ water purification system (Millipore Iberia, Madrid, Spain), was used for the preparation of solutions, chromatographic eluents and glassware washing. HPLC gradient methanol (Fisher, Waltham, MA) was used for standard solutions preparation and as chromatographic mobile phase. HPLC gradient grade acetonitrile (Fisher) was used for the extractions. Formic acid (99\%, VWR, Radnor, PA) was used to acidify the aqueous mobile phase, prepared with high-purity water. All eluents were filtered through a Nylon filter $(0.45 \mu \mathrm{m}$ pore size, Whatman, Pittsburgh, PA) and degassed before use. 
Caffeic acid (98\%), chlorogenic acid (95\%), p-coumaric acid (98\%), quercetin dihydrate (98\%), transanethole (99\%) were purchased from Sigma-Aldrich (Steinheim, Germany). Stock standard solutions of these compounds were prepared in methanol. Ammonium acetate (Merck, Darmstadt, Germany), sodium carbonate (Panreac, Barcelona, Spain), potassium carbonate (Merck), dihydrogen phosphate (Pronalab, Tlalnepantla, Mexico) and ammonium sulphate ((NH4)2SO4) (BDH Prolabo, Radnor, PA) were of analytical grade and were used without further purification. Xanthohumol $(98 \%$, Hopsteiner, Mainburg, Germany) was prepared in ethanol (95.5\%, Merck) for use as internal standard. Terpene standards (CAN-TERP-MIX1 and CAN-TERP-MIX2) used for GC analysis were obtained from SPEX Europe (Stanmore, UK).

Fennel (Foeniculum vulgare Mill.) dried seed samples were purchased in local markets.

\section{Extraction procedure}

The experimental procedure used for the development of this work was based on previous procedures using the SALLE technique, developed by our research group (Valente et al., 2013a) (Figure 1). In $50 \mathrm{~mL}$ plastic tubes, fennel seeds $(0.5 \mathrm{~g})$ were extracted with $10 \mathrm{~mL}$ of solvent $(50 \%$ of acetonitrile in water) and $1 \mathrm{~g}$ of (NH4)2SO4 by decoction using mechanical stirring for $37 \mathrm{~min}$, at room temperature. After the extraction, the tubes were centrifuged for 2 min at 7750 relative centrifugal force (RCF) for phase separation and an aliquot of the upper (organic) phase was collected for HPLC analysis. For GC analysis, an extra step was included to remove any water residue and possible interfering compounds (sugars, pigments, etc.); $1 \mathrm{~mL}$ of organic extract was added to a dispersive solid-phase extraction (d-SPE) tube containing $150 \mathrm{mg}$ magnesium sulphate (MgSO4), 50 $\mathrm{mg}$ of primary and secondary amine (PSA) and $50 \mathrm{mg} \mathrm{C18}$. All analyses were carried out in triplicate.

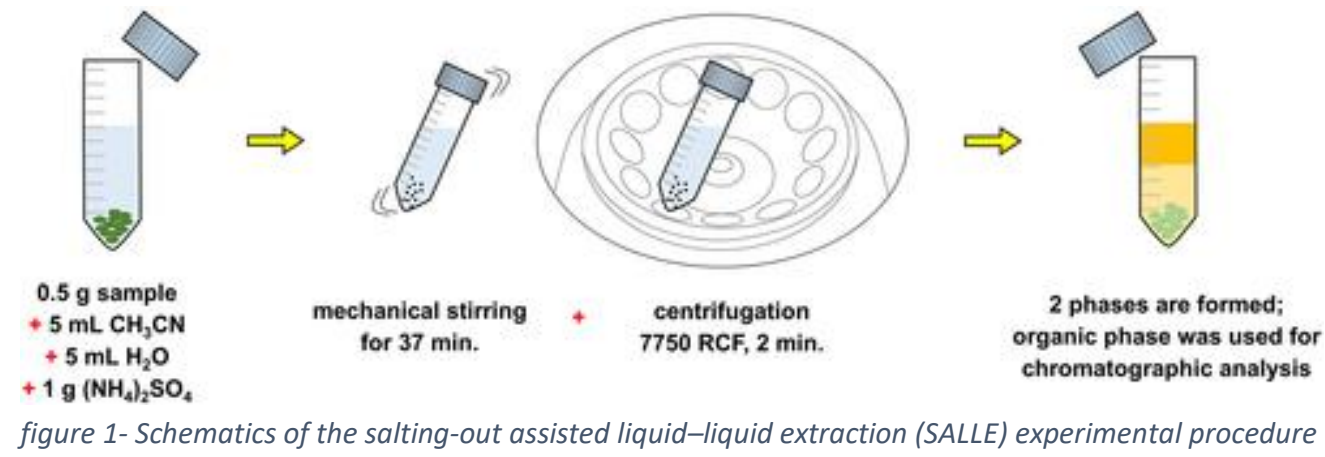

HPLC-UV analysis

Fennel extracts were analysed by HPLC-UV using a Jasco (Jasco Corporation, Tokyo, Japan) chromatographic system consisting of a low-pressure quaternary gradient unit (model PU-2089 Plus) with an on-line degasser (model DG-1580-54), an autosampler (model AS-950) and a photodiode array detector (model MD-1510). The system control and data analysis was done with Jasco ChromPass Chromatography Data software (version 1.7.403.1). Separations were achieved at room temperature on a Gemini C18 column $(250 \mathrm{~mm} \times 4.6 \mathrm{~mm} ; 5 \mu \mathrm{m}$ particle size $)$ and a guard column $(4 \mathrm{~mm} \times 3.0 \mathrm{~mm}$ ) from Phenomenex (Torrance, CA). The mobile phase, under gradient conditions at $0.8 \mathrm{~mL} / \mathrm{min}$, was composed of (A) methanol and (B) $0.1 \%$ formic acid in water. Gradient programme was set as follows: 0 to $40 \mathrm{~min}$, linear increase from $10 \%$ to $30 \%$ of A; 40 to $60 \mathrm{~min}$, increase to $45 \%$ of A; 60 to $90 \mathrm{~min}$, linear increase to $100 \%$ A and conditions maintained for $5 \mathrm{~min}$; return to initial conditions in $15 \mathrm{~min}$ and conditions maintained for $10 \mathrm{~min}$ before the next injection. Sample injection volume was $20 \mu \mathrm{L}$. The photodiode array detection was conducted by scanning between 190 and $600 \mathrm{~nm}$. Analytes in each sample were identified by comparing their retention times and UV-vis spectra with those of standard compounds, and by HPLC-MS/MS analysis. A chromatogram obtained for the HPLC-UV analysis (at $280 \mathrm{~nm}$ ) of an extract is shown in Figure 2. 


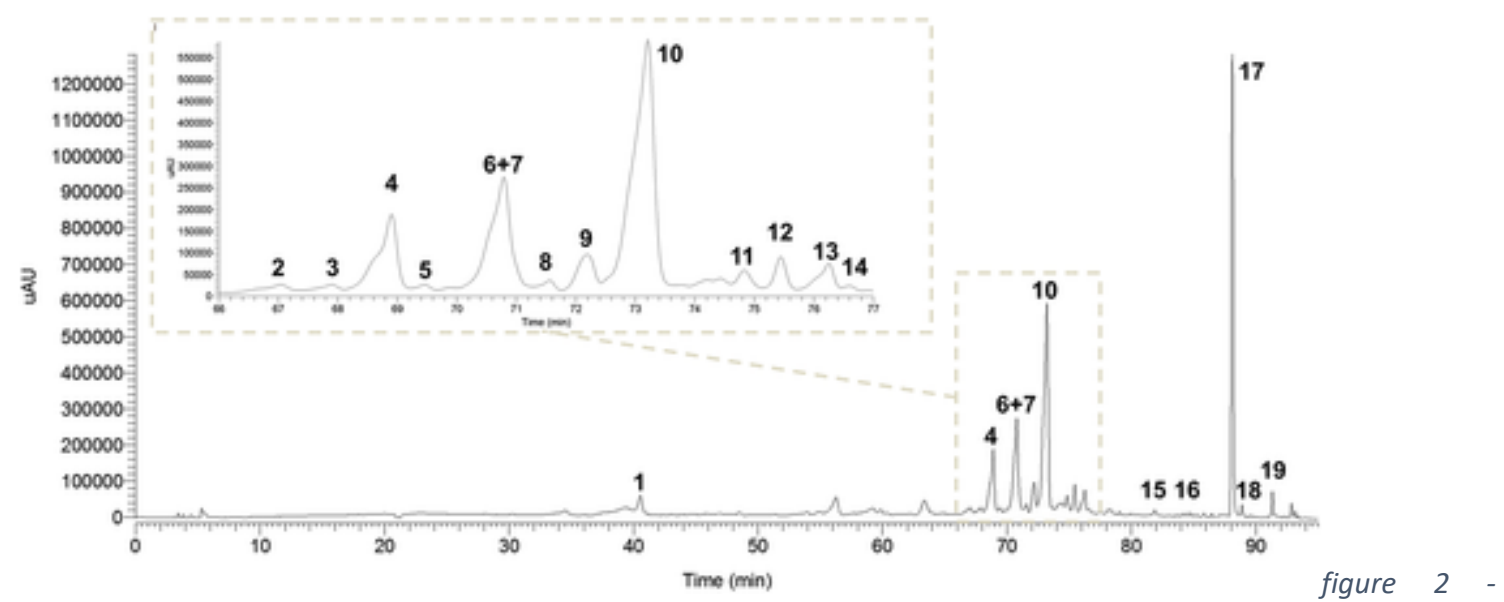

HPLC-UV chromatogram $(280 \mathrm{~nm})$ of fennel seeds extract. Numbered peaks correspond to tentatively identified compounds that can be ascribed to Table 2

HPLC-DAD-MS/MS analysis

The qualitative study of the extracts' composition was performed by HPLC coupled on-line with electrospray ionisation (ESI) MS. The HPLC system (Thermo Electron Corporation, Waltham, MA) was composed of a low-pressure quaternary pump with autosampler (200-vial capacity sample) and a diode array detector (DAD) (Finnigan Surveyor Plus, Thermo Fisher Scientific). A Gemini C18 column $(150 \mathrm{~mm} \times 4.6 \mathrm{~mm} ; 3 \mu \mathrm{m}$ particle size $)$ and a guard column $(4 \mathrm{~mm} \times 3.0 \mathrm{~mm})$ from Phenomenex were used at room temperature. Separations were achieved in the same conditions as for HPLC-UV analysis but at a flow rate of $0.4 \mathrm{~mL} / \mathrm{min}$ with injection of $25 \mu \mathrm{L}$ of sample. A quadrupole ion-trap mass spectrometer (Finnigan LCQ Deca XP Plus) equipped with an ESI source was used in the following conditions: capillary temperature, $325^{\circ} \mathrm{C}$; source voltage, $5.0 \mathrm{kV}$; capillary voltage, $4.0 \mathrm{~V}$; sheath gas (N2) flow at 40 arbitrary units and auxiliary gas (N2) flow at 15 arbitrary units. The mass detection was performed in the range 160-1000 m/z. XCalibur software Version 2.2 (Thermo Electron Corporation) was used for data acquisition and processing.

GC-MS analysis

Fennel extracts were characterised by GC-MS analysis using a Thermo Scientific Trace 1300, ISQ Single Quadrupole MS and a TraceGOLD TG-5MS $(60 \mathrm{~m} \times 0.25 \mathrm{~mm} ; 0.25 \mu \mathrm{m})$ from Thermo Scientific. The injector and detector temperatures were maintained at $250^{\circ} \mathrm{C}$. The oven temperature was programmed to $40^{\circ} \mathrm{C}$ for $2 \mathrm{~min}$, raised to $250^{\circ} \mathrm{C}$ at a rate of $6^{\circ} \mathrm{C} / \mathrm{min}$, and kept steady at $250^{\circ} \mathrm{C}$ for additional $5 \mathrm{~min}$. Helium was the carrier gas at a flow rate of $1 \mathrm{~mL} / \mathrm{min}$. A sample of $1 \mu \mathrm{L}$ of extract was injected in splitless mode.

The MS detector was operated in electron-impact ionisation (EI) mode with a mass scan range from $\mathrm{m} / \mathrm{z} 50$ to 350 at $70 \mathrm{eV}$. The compounds were identified by comparing their GC retention indices and mass spectra with published data and National Institute of Standards and Technology (NIST) mass spectra library data provided by the software of GC-MS system, and with standards. Compounds are reported as a relative percentage of the total extract by peak area.

Experimental design

A total of 19 runs were performed for optimising the three individual experimental parameters in the current model. Eight points of a factorial design with three factors at two levels $(\alpha= \pm 1.00)$, six axial star points at a distance $\alpha= \pm 2.00$ from the centre point. The centre point had five replicates. The experiments were performed in a randomised order to minimise bias effect (Mendes et al., 2016). The optimisation was carried out using the response surface methodology.

All statistical analyses were made using the software Statistica version 6.0 (StatSoft, Tulsa, OK), namely, multifactor analysis of variance (ANOVA) and response surface three-dimensional (3D) plots. 


\section{Results and discussion}

The optimisation of SALLE for phytochemical analysis was evaluated by the analysis of the nonvolatile phenolic compounds extracted from fennel seeds. For this purpose, the relative extraction efficiency was evaluated using the total peak area obtained by the analysis of the extracts by HPLCUV analysis.

Preliminary studies

Before using the experimental design, preliminary experiments were carried out in order to select the relevant variables for the extraction of phenolic compounds from the fennel seeds as well as the experimental range for the factors.

The first studied experimental parameter was the sample mass/solvent volume ratio. It was observed that higher ratios resulted in higher chromatographic signals. A sample mass of $0.5 \mathrm{~g}$ and a solvent volume of $10 \mathrm{~mL}$ were considered to result in a good extraction efficiency and was the best experimental conditions to achieve a good phase separation.

One of the most important parameters in SALLE is the type of salt used as salting-out agent (Valente et al., 2013a). The salts used for these studies were selected according to our previous results (Valente et al., 2013a). CH3COONH4, Na2CO3, K2CO3, NaCl, NaH2PO4, Na2SO4 and (NH4)2SO4 were tested at a concentration of $0.5 \mathrm{~mol} / \mathrm{L}$ in a mixture of acetonitrile/water $(1: 1, \mathrm{v} / \mathrm{v})$. The extraction of phenolic compounds was possible with all the salts tested (Figure 3). However, it was verified that the extraction efficiency of phenolics using carbonate salts was the least efficient. From the salts tested, the best result was observed for (NH4)2SO4 being the salt chosen to the subsequent experiments. Besides, this salt has the advantage of being compatible with MS analysis.

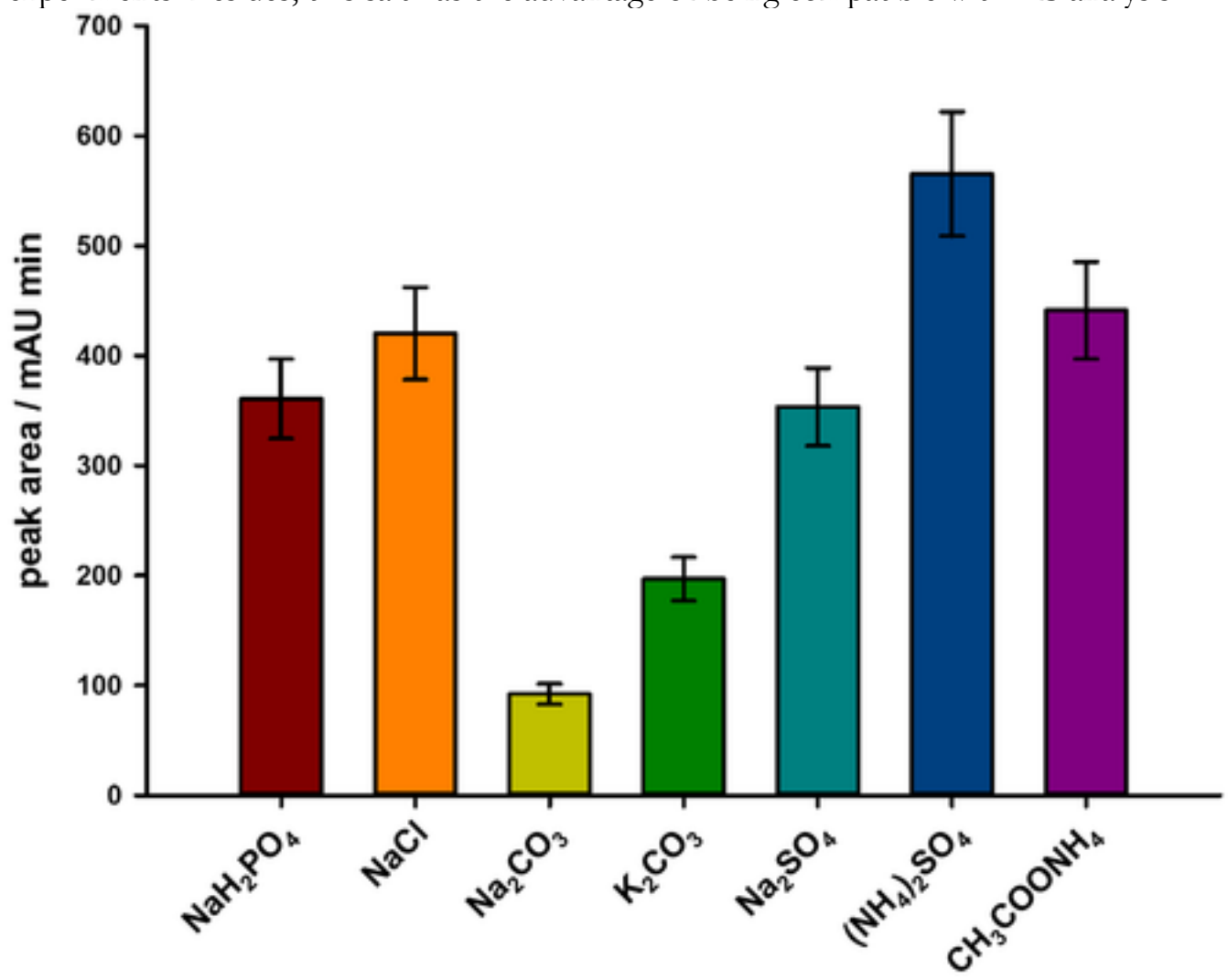

figure 3 -Effect of different salts used for SALLE in the extraction efficiency of non-volatile phenolic compounds.

Another important parameter is the solvent composition; the acetonitrile/water ratio not only affects the formation of the biphasic system, but also affects the extraction efficiency (Valente et al., 2013a). Mixtures composed of acetonitrile and water in the range $40-60 \%$ were shown to be the best conditions for phase separation. 


\section{Surface response methodology analysis}

In the preliminary tests, it was possible to establish the sample's quantity, the solvent's volume and the salt nature; the other important parameters (salt concentration, solvent composition and extraction time) were optimised using a central composite design. The response values, expressed as total peak area, at different experimental combination for coded variables are listed in Table S1 in the Supporting Information. The results in the initial set of experiments (runs 1-13 in Table S1) were fitted to a first-order model, additional runs were performed to improve model adjustment (Moreira et al., 2012). The final optimised conditions are shown in Table 1.

\begin{tabular}{|c|c|c|}
\hline Variable & Studied range & Optimum value \\
\hline Organic solvent percentage (\%) & $33-67$ & 50 \\
\hline Extraction time (min) & $3-37$ & 37 \\
\hline Salt concentration (mol/L) & $0.66-2.30$ & 0.7 \\
\hline
\end{tabular}

Phenolic profile of the fennel extracts

The compounds extracted from fennel seeds by the developed methodology were identified by HPLC-MS/MS analysis by comparing retention time, UV and MS data with those of reference standards. Otherwise, the extracted phenolics were tentatively identified based on literature data. The list of identified compounds is presented in Table 2. Identification of the compounds was mainly based on the results from the negative ion mode analysis; in some cases the positive ion mode allowed the confirmation of the peaks identification.

Table 2. Identified compounds by HPLC-MS/MS in the fennel seeds extracts obtained using the developed methodology 


\begin{tabular}{|c|c|c|c|c|c|c|c|}
\hline Peak & $t_{\mathrm{A}}(\min )$ & $\begin{array}{c}\text { UV } \\
\text { bands (nm) }\end{array}$ & $\begin{array}{c}{[\mathrm{M}-\mathrm{H}]^{-} \mathrm{m} / \mathrm{z}} \\
\text { (\% base peak) }\end{array}$ & $\begin{array}{c}\text { MS/MS } m / z \\
\text { ( } \% \text { base peak) }\end{array}$ & $\begin{array}{l}{[\mathrm{M}+\mathrm{H}]^{+} \mathrm{m} / \mathrm{z}} \\
\text { (\% base peak) }\end{array}$ & $\begin{array}{c}\text { MS/MS m/z } \\
\text { ( } \% \text { base peak) }\end{array}$ & $\begin{array}{l}\text { Assigned } \\
\text { identity }\end{array}$ \\
\hline 1 & 40.5 & $\begin{array}{c}246,297 \mathrm{sh} \\
327\end{array}$ & $\begin{array}{r}353(100), 421(93) \\
399(91), 489(40)\end{array}$ & $\mathrm{MS}^{2}$ [353]: $191(100)$ & $\begin{array}{c}355(100), 372(97) \\
731(28)\end{array}$ & $\begin{array}{l}\text { MS }^{2}[355]: \\
163(100)\end{array}$ & $\begin{array}{l}\text { 5-caffeoylquinic acid } \\
\text { (chlorogenic acid) }\end{array}$ \\
\hline 2 & 67.0 & $\begin{array}{c}252,300 \text { sh, } \\
324\end{array}$ & $515(100), 583(63)$ & $\begin{array}{l}\mathrm{MS}^{2}[515] ; 353(100) \\
\quad \mathrm{MS}^{3}[515 \rightarrow 353] \\
191(100)\end{array}$ & - & - & 1,5-dicaffeoylquinic acid \\
\hline 3 & 67.9 & $\begin{array}{c}252,300 \text { sh } \\
327\end{array}$ & $601(100)$ & $\begin{array}{c}M^{2}{ }^{2}[601] \text { : } 395(100) \\
515(45), 557(42), \\
439(17), 233(6) \\
M S^{3}[601 \rightarrow 395] \\
179(100), 233(71) \\
215(65), 335(49)\end{array}$ & - & - & $\begin{array}{l}\text { dicaffeoylquinic acid } \\
\text { derivative }\end{array}$ \\
\hline 4 & 68.9 & $\begin{array}{c}246,300 \text { sh, } \\
330\end{array}$ & $515(100), 583(44)$ & $\begin{array}{l}\text { MS }^{2}[515]: 353(100) \\
\text { MS }^{3}[515 \rightarrow 353]: 191 \\
(100), 179(11)\end{array}$ & $\begin{array}{r}539(100), 517(46) \\
534(34), 355(17)\end{array}$ & $\begin{array}{l}M^{2}{ }^{2}[539]: 377(100), \\
359(48), 331(12) \\
M^{3}[539 \rightarrow 377] \\
218(100), 215(66), \\
163(39), 185(40), \\
197(37), 359(35), \\
179(24)\end{array}$ & 3,5-dicaffeoylquinic acid \\
\hline 5 & 69.5 & 290 sh, 320 & $475(100)$ & - & - & - & unknown \\
\hline 6 & 70.8 & $\begin{array}{c}249,300 \text { sh, } \\
330\end{array}$ & $\begin{array}{c}601(100), 623(23) \\
463(12)\end{array}$ & $\begin{array}{c}\mathrm{MS}^{2}[601] ; \\
515(85), 557(100), \\
439(58), \\
377(20), 421(12) \\
\mathrm{MS}^{3}[601 \rightarrow 395] ; \\
233(100), 335(16)\end{array}$ & $\begin{array}{c}625(100), 620(85) \\
465(29)\end{array}$ & $\begin{array}{c}\mathrm{MS}^{2}[625] ; \\
581(41), 4193(100), \\
563(23), 401(17), \\
445(12) \\
\mathrm{MS}^{3}[625 \rightarrow 463] \\
401(100), 419(77) \\
377(67), 257(39), \\
221(25), 319(21)\end{array}$ & $\begin{array}{l}\text { malonyl-1,4-0-dicaffeoylquinic } \\
\text { acid }\end{array}$ \\
\hline 7 & 71.0 & $\begin{array}{c}255,305 \text { sh } \\
342\end{array}$ & $\begin{array}{c}463(100), 601(88) \\
577(43)\end{array}$ & $\begin{array}{c}\mathrm{MS}^{2} \text { [463]: } 301(100) \\
\text { MS3 [463 } \rightarrow 301] \\
179(100), 271(51), \\
255(30), 151(26)\end{array}$ & - & - & $\begin{array}{l}\text { quercetin-3-0-glucoside } \\
\text { (iso quercitrin) }\end{array}$ \\
\hline 8 & 71.6 & $\begin{array}{c}252,300 \text { sh } \\
327\end{array}$ & $\begin{array}{c}515(100), 583(72) \\
561(61)\end{array}$ & $\begin{array}{l}M^{M S^{2}} \text { [515]: 353(100) } \\
\left.\text { MS }^{3} \text { [515 } \rightarrow 353\right] \text { : } \\
191(100)\end{array}$ & - & - & 1,3-dicaffeoylquinic acid \\
\hline 9 & 72.2 & $\begin{array}{c}252,300 \text { sh } \\
327\end{array}$ & $\begin{array}{r}601(100), 623(41) \\
512(12), 644(12)\end{array}$ & $\begin{array}{c}M^{2}{ }^{2}[601]: 395(100), \\
557(59), 439(53), \\
515(43), 233(22) \\
M^{3}[601 \rightarrow 395]: \\
233(100)\end{array}$ & - & - & $\begin{array}{l}\text { malonyl-4,5-0-dicaffeoylquinic } \\
\text { acid }\end{array}$ \\
\hline
\end{tabular}




\begin{tabular}{|c|c|c|c|c|c|c|c|}
\hline Peak & $\mathrm{t}_{\mathrm{B}}(\mathrm{min})$ & $\begin{array}{c}\text { UV } \\
\text { bands (nm) }\end{array}$ & $\begin{array}{l}{[\mathrm{M}-\mathrm{H}]^{-} \mathrm{m} / \mathrm{z}} \\
\text { (\% base peak) }\end{array}$ & $\begin{array}{l}\text { MS/MS m/z } \\
\text { (\% base peak) }\end{array}$ & $\begin{array}{l}{\left[\mathrm{M}+\mathrm{H}^{+} \mathrm{m} / \mathrm{z}\right.} \\
\text { (\% base peak) }\end{array}$ & $\begin{array}{l}\text { MS/MS m/z } \\
\text { (\% base peak) }\end{array}$ & $\begin{array}{l}\text { Assigned } \\
\text { identity }\end{array}$ \\
\hline 12 & 75.4 & $\begin{array}{c}264,300 \\
324\end{array}$ & - & - & $163(100)$ & $\begin{array}{l}\text { MS }^{2} \text { [163]: } 145(100), \\
\text { 107(14), 135(14), } \\
107(12)\end{array}$ & unknown \\
\hline 13 & 76.3 & $\begin{array}{c}264,300 \text { sh, } \\
345\end{array}$ & $\begin{array}{r}461(100), 529(82) \\
507(81), 483(25)\end{array}$ & $\begin{array}{l}M^{2}{ }^{2}[461]: 285(100) \\
M^{3}[461 \rightarrow 285] \\
257(100), 229(75), \\
213(59), 199(28), \\
165(16)\end{array}$ & $\begin{array}{c}463(100), 485(57) \\
947(22)\end{array}$ & $\begin{array}{c}\mathrm{MS}^{2}[463]: 287(100) \\
\mathrm{MS}^{3}[463 \rightarrow 287]: \\
241(100), 287(66) \\
199(58), 135(45) \\
165(37), 213(40)\end{array}$ & kaempferol-3-O-glucoronide \\
\hline 14 & 76.6 & 255,309 & $491(100)$ & $\begin{array}{l}\mathrm{MS}^{2} \text { [491]: } 315(100) \\
\mathrm{MS}^{3}[491 \rightarrow 315] \\
300(100), 2550 \\
2730,2870\end{array}$ & - & - & isorhamnetin-3-O-glucoronide \\
\hline 15 & 81.87 & $\begin{array}{c}261,303 \\
363\end{array}$ & $285(100)$ & - & & & kaempferol \\
\hline 16 & 84.21 & - & $329(100)$ & $\begin{array}{l}\text { MS }^{2}[329]: \text { 229(100), } \\
211(55), 311(43) \\
\text { MS }^{3}[329 \rightarrow 229] \\
125(100)\end{array}$ & & & unknown \\
\hline 17 & 88.1 & 276 & - & - & - & - & unknown \\
\hline 18 & 88.9 & 258,300 & - & - & - & - & unknown \\
\hline 19 & 91.3 & $\begin{array}{c}243,276 \\
369\end{array}$ & $353(100)$ & $\begin{array}{l}\mathrm{MS}^{2}[353]: 233(100), \\
247(7) \\
\mathrm{MS}^{3}[353 \rightarrow 233 \text {; } \\
218(100), 189(49), \\
159(45), 165(29), \\
189(29)\end{array}$ & $647(100)$ & - & unknown \\
\hline
\end{tabular}


Several caffeoylquinic and dicaffeoylquinic acids were identified in the fennel seed extracts through the presence of the characteristic fragments with $\mathrm{m} / \mathrm{z} 515$ and 353 in the negative ion mode (Clifford et al., 2003) and a characteristic UV spectrum with an absorption maximum at $324 \mathrm{~nm}$.

Peak at 40.54 min was assigned as 5-caffeoylquinic acid (chlorogenic acid) showing an intense molecular ion $[\mathrm{M}-\mathrm{H}]$ - with $\mathrm{m} / \mathrm{z} 353$ and a MS2 fragment at $\mathrm{m} / \mathrm{z}$ 191. Three isomers of dicaffeoylquinic acid (m/z 515 in negative ion mode) were identified in the extracts at 67.04, 68.90 and $71.56 \mathrm{~min}$ (Parejo et al., 2004). Their identification and the discrimination of the isomers was based on the literature data (Clifford et al., 2005).

Two dicaffeoylquinic acid derivatives containing a malonyl group in their structure were present in the extract. Peaks at 70.79 and 72.19 min displayed a $[\mathrm{M}-\mathrm{H}]-$ ion at $\mathrm{m} / \mathrm{z} 601$ and gave characteristic fragment ions of malonyl at $\mathrm{m} / \mathrm{z} 557$ ([M-H-44]-) and $\mathrm{m} / \mathrm{z} 515$ ([M-H-86]-). The differences between the fragment ions intensities enabled the identification of compounds based on the literature data (Gouveia and Castilho, 2011). Hence, peaks at $70.79 \mathrm{~min}$ and $72.19 \mathrm{~min}$ were attributed to malonyl-1,4-O-dicaffeoylquinic acid (due to the presence of an intense ion at $\mathrm{m} / \mathrm{z} 515$ ) and malonyl4,5-dicaffeoylquinic acid, respectively.

Several flavonoids derivatives were also identified in the obtained extracts, quercetin, isorhamnetin and kaempferol glycosides.

Peak at 71.00 min displayed a $[\mathrm{M}-\mathrm{H}]-$ ion at $\mathrm{m} / \mathrm{z} 463$. The MS2 spectrum had a base peak at $\mathrm{m} / \mathrm{z}$ 301 , corresponding to the loss of a hexoside residue (162 Da). Fragmentation of base peak led to quercetin characteristic ions at m/z 179, 271 ([M-H-CH2O]-), 255 ([M-H-H2OCO]-) and 151. This compound was identified as quercetin-3-O-glucoside (isoquercitrin) by comparison of MSn with the literature data (Gouveia and Castilho, 2011).

A parent ion at $\mathrm{m} / \mathrm{z} 477$ was found at $\mathrm{tr}=73.21 \mathrm{~min}$, attributed to quercetin-3-O-glucoronide (miquelianin), due to the presence of the characteristic MSn fragment ions of quercetin described earlier.

An $\mathrm{m} / \mathrm{z}$ of 477 was also found at 74.43 min although producing a different fragmentation pattern. The MS2 fragmentation of this ion produced an intense ion peak of $\mathrm{m} / \mathrm{z} 314$ ([M-H-163]-) and a MS3 resulted in characteristic isorhamnetin ions of $\mathrm{m} / \mathrm{z} 285,271$ and 300. This peak was attributed to isorhamnetin-3-O-glucoside (Parejo et al., 2004). Another isorhamnetin derivative (isorhamnetin3-O-glucuronide) was found at $76.62 \mathrm{~min}$ with a parent ion of $\mathrm{m} / \mathrm{z} 491$ which produced a MS2 intense fragment of $\mathrm{m} / \mathrm{z} 315$ and MS3 fragment ion $\mathrm{m} / \mathrm{z} 300$.

Kaempferol-3-O-glucoronide was identified at 76.25 min due to the presence of a MS2 fragment ion at $\mathrm{m} / \mathrm{z} 285$ corresponding to kaempferol, which resulted in the fragmentation of the intense parent ion $\mathrm{m} / \mathrm{z} 461$ by the loss of $176 \mathrm{Da}$.

Volatile composition of the extracts

The volatile composition of the fennel seed extracts was characterised by GC-MS analysis. The identified compounds, their retention time and relative peak area are listed in Table 3. A total of 26 compounds were identified in the extracts. The main component was estragole (58.47\%) followed by limonene $(17.70 \%)$, fenchone $(5.15 \%), \alpha$-pinene $(2.39 \%)$ and trans-anethole $(1.61 \%)$. Other compounds were found to be minor components $(<1 \%$ of the total peak area). The profile obtained 
for the SALLE extracts of fennel seeds was similar to that reported by other authors (Yu et al., 2013) . Shahat et al. (2011) identified 18 compounds in the essential oil of dried seeds of Foeniculum vulgare var. vulgare and also found that estragole (57.94\%), limonene (20.64\%), fenchone (7.22\%), $\alpha$-pinene $(3.61 \%)$ and trans-anethole (4.99\%) were the main components of the seeds oil. The results obtained with the developed SALLE methodology were also in agreement with those obtained by other authors (Miguel et al., 2010) that verified that estragole was the main volatile compound present in dried parts of the fennel plant.

\begin{tabular}{|c|c|c|c|}
\hline Peak & $t_{R}(\min )$ & Assigned identity & $\begin{array}{c}\text { Peak } \\
\text { area }(\%)^{\mathrm{a}}\end{array}$ \\
\hline 1 & 13.23 & $\alpha$-pinene & 2.65 \\
\hline 2 & 13.69 & camphene & 0.10 \\
\hline 3 & 14.03 & benzaldehyde & Trace $^{b}$ \\
\hline 4 & 14.39 & sabinene & 0.76 \\
\hline 5 & 14.53 & $\beta$-pinene & 0.15 \\
\hline 6 & 14.75 & $\beta$-myrcene & 0.96 \\
\hline 7 & 15.24 & 3-carene & 0.36 \\
\hline 8 & 15.60 & o-cymene & 0.25 \\
\hline 9 & 15.91 & limonene & 19.56 \\
\hline 10 & 16.04 & $\begin{array}{l}\text { 1,8-cineole } \\
\text { (eucalyptol) }\end{array}$ & 0.58 \\
\hline 11 & 16.31 & cis- $\beta$-ocimene & 0.04 \\
\hline 12 & 16.71 & $\gamma$-terpinene & 1.07 \\
\hline 13 & 17.6 & fenchone & 5.70 \\
\hline 14 & 18.47 & $\begin{array}{l}\text { 1,5,5,6-tetramethyl-1,3- } \\
\text { cyclohexadiene } \\
\text { ( } \alpha \text {-pyronene) }\end{array}$ & 0.47 \\
\hline 15 & 19.14 & camphor & 0.08 \\
\hline 16 & 20.4 & estragole & 64.61 \\
\hline 17 & 20.88 & cumin aldehyde & 0.13 \\
\hline 18 & 21.29 & fenchyl acetate & 0.22 \\
\hline 19 & 21.54 & carvone & 0.09 \\
\hline 20 & 21.68 & cis-anethole & 0.04 \\
\hline 21 & 21.77 & p-anisaldehyde & 0.13 \\
\hline 22 & 22.49 & trans-anethole & 1.77 \\
\hline 23 & 27.1 & germacrene D & 0.09 \\
\hline 24 & 27.35 & $\begin{array}{l}\text { 2,4-bis(1,1-dimethylethyl)- } \\
\text { phenol }\end{array}$ & 0.07 \\
\hline 25 & 29.79 & apiole (dill.) & 0.10 \\
\hline 26 & 34.89 & methyl palmitate & 0.03 \\
\hline \multicolumn{4}{|c|}{$\begin{array}{l}\text { "Relative percentage of the total peak area of the identified } \\
\text { compounds. } \\
\text { 'Trace: } \leq 0.01 \% \text {. }\end{array}$} \\
\hline
\end{tabular}

\section{Final remarks}

This work was used as a proof-of-concept for the SALLE aiming plant characterisation. Authors advocate its merits namely its simplicity, low-cost and versatility. SALLE was applied in the LC-MS and GC-MS analysis. Optimised conditions, obtained by crafted design of experiments, were the following: 1:1 organic/aqueous phases, $37 \mathrm{~min}$ time of extraction and $0.7 \mathrm{~mol} / \mathrm{L}$ as the salt 
((NH4)2SO4) concentration. Several relevant volatile and non-volatile compounds were found ranging from phenolic compounds to quercetin derivatives and various terpenic compounds.

\section{Acknowledgments}

This work received financial support from FCT/MEC through national funds and co-financed by FEDER, under the Partnership Agreement PT2020-UID/QUI/50006/2013POCI/01/0145/FEDER/007265. LMG (SFRH/BPD/76544/2011) and MMM (SFRH/BPD/97049/2013) wish to acknowledge Fundação para a Ciência e a Tecnologia for their postdoctoral grants. IMV (SFRH/BPD/111181/2015) wishes to acknowledge FCT for her postdoctoral grant funded by the Portuguese Ministry of Education and Science and by the European Social Fund within the 2014-2020 Strategic Framework.

\section{References}

Ahmed S, Mahmoud AM. 2015. A novel salting-out assisted extraction coupled with HPLC-fluorescence detection for trace determination of vitamin $\mathrm{K}$ homologues in human plasma. Talanta 144: 480-487.

Akha O, Rabiei K, Kashi Z, Bahar A, Zaeif-Khorasani E, Kosaryan M, Saeedi M, Ebrahimzadeh MA, Emadian O. 2014. The effect of fennel (Foeniculum vulgare) gel 3\% in decreasing hair thickness in idiopathic mild to moderate hirsutism. A randomized placebo controlled clinical trial. Caspian J Intern Med 5: 26-29.

Azevedo CF, Quirino ZGM, Rego ER, Bruno RLA, Silva GZ. 2012. Anatomical aspects of the Foeniculum vulgare Mill. seedling. Rev Bras Plant Med 14: 197-204.

Clifford MN, Johnston KL, Knight S, Kuhnert N. 2003. Hierarchical scheme for LC-MSn identification of chlorogenic acids. J Agric Food Chem 51: 2900-2911.

Clifford MN, Knight S, Kuhnert N. 2005. Discriminating between the six isomers of dicaffeoylquinic acid by LC-MSn . J Agric Food Chem 53: 3821-3832.

Díaz-Maroto MC, Pérez-Coello MS, Esteban J, Sanz J. 2006. Comparison of the volatile composition of wild fennel samples (Foeniculum vulgare Mill.) from central Spain. J Agric Food Chem 54: 6814-6818.

Gori L, Gallo E, Mascherini V, Mugelli A, Vannacci A, Firenzuoli F. 2012. Can Estragole in fennel seed decoctions really be considered a danger for human health? A fennel safety update. Evid Based Complement Alternat Med 2012: 10.

Gouveia S, Castilho PC. 2011. Characterisation of phenolic acid derivatives and flavonoids from different morphological parts of Helichrysum obconicum by a RP-HPLCDAD-()-ESI-MSn method. Food Chem 129: 333-344. 
Huie C. 2002. A review of modern sample-preparation techniques for the extraction and analysis of medicinal plants. Anal Bioanal Chem 373: 23-30.

Jahromi BN, Tartifizadeh A, Khabnadideh S. 2003. Comparison of fennel and mefenamic acid for the treatment of primary dysmenorrhea. Int J Gynecol Obstet 80: 153-157.

Matkovich CE, Christian GD. 1973. Salting-out of acetone from water. Basis of a new solvent extraction system. Anal Chem 45: 1915-1921.

Mendes M, Carvalho AP, Magalhães JMCS, Moreira M, Guido L, Gomes AM, DelerueMatos C. 2016. Response surface evaluation of microwaveassisted extraction conditions for Lycium barbarum bioactive compounds. Innov Food Sci Emerg 33: 319-326.

Miguel MG, Cruz C, Faleiro L, Simoes MT, Figueiredo AC, Barroso JG, Pedro LG. 2010. Foeniculum vulgare essential oils: Chemical composition, antioxidant and antimicrobial activities. Nat Prod Commun 5: 319-328.

Moreira MM, Morais S, Barros AA, Delerue-Matos C, Guido LF. 2012. A novel application of microwave-assisted extraction of polyphenols from brewer's spent grain with HPLCDAD-MS analysis. Anal Bioanal Chem 403: 1019-1029.

Parejo I, Jauregui O, Sanchez-Rabaneda F, Viladomat F, Bastida J, Codina C. 2004. Separation and characterization of phenolic compounds in fennel (Foeniculum vulgare) using liquid chromatography-negative electrospray ionization tandem mass spectrometry. J Agric Food Chem 52: 3679-3687.

Shahat AA, Ibrahim AY, Hendawy SF, Omer EA, Hammouda FM, AbdelRahman FH, Saleh MA. 2011. Chemical composition, antimicrobial and antioxidant activities of essential oils from organically cultivated fennel cultivars. Molecules 16: 1366-1377.

Silva CL, Haesen N, Câmara JS. 2012. A new and improved strategy combining a dispersive-solid phase extraction-based multiclass method with ultra high pressure liquid chromatography for analysis of low molecular weight polyphenols in vegetables. J Chromatogr A 1260: 154-163.

Steuer B, Schulz H. 2003. Near-infrared analysis of fennel (Foeniculum vulgare Miller) on different spectrometers-basic considerations for a reliable network. Phytochem Analysis 14: 285-289. 
Valente IM, Gonçalves LM, Rodrigues JA. 2013a. Another glimpse over the salting-out assisted liquid-liquid extraction in acetonitrile/water mixtures. J Chromatogr A 1308: 58-62.

Valente IM, Santos CM, Moreira MM, Rodrigues JA. 2013b. New application of the QuEChERS methodology for the determination of volatile phenols in beverages by liquid chromatography. J Chromatogr A 1271: 27-32.

Yang Y, Xu Q, Zhou L, Zhong D, Chen X. 2015. High-throughput salting-outassisted liquidliquid extraction for the simultaneous determination of atorvastatin, orthohydroxyatorvastatin, and para-hydroxyatorvastatin in human plasma using ultrafast liquid chromatography with tandem mass spectrometry. J Sep Sci 38: 1026-1034.

Yu C, Yang J, Wang Y, Wei H, Zhang H, Shi Y. 2013. Ultrasonic nebulisation extraction: Extraction column coupled with liquid phase microextraction for analysis of the volatile organic compounds in Foeniculum vulgare Mill. as a model. Phytochem Analysis 24: 296-302.

\section{Supporting information}

Additional supporting information may be found in the online version of this article at the publisher's web site. 